\title{
Revisitando a perspectiva de James MacGregor Burns: qual é a ideia por trás do conceito de liderança transformacional?
}

\author{
Revisiting James MacGregor Burns' perspective: what is the idea behind the concept of \\ transformational leadership?
}

\author{
Pedro Alessandro Calaça ${ }^{1}$ \\ Fabio Vizeu ${ }^{2}$
}

\begin{abstract}
Resumo
Na Administração, a liderança é vinculada ao interesse na eficiência produtiva, tendo como pressuposto a capacidade de líderes e liderados atingirem os resultados organizacionais. Todavia, a liderança é matéria mais ampla do que pode julgar essa concepção. Por entender que essa é a perspectiva adotada no texto seminal de Burns (1978) sobre liderança transformacional, propomos neste estudo revisitar essa obra, para contrapor seus principais argumentos em relação àqueles formulados por autores de liderança transformacional na área de Administração. Para tanto, adotamos a análise sócio-histórica, como proposta por Stefani e Vizeu (2011), a primeira etapa da hermenêutica de profundidade (THOMPSON, 2000), um método que visa a evitar o erro da livre interpretação de uma obra contextualmente situada. Assim, concluímos que o ponto central da liderança transformacional, para Burns, é a questão do desenvolvimento moral e o distanciamento na relação utilitária entre líder e liderados. Esses dois pontos são reforçados ao longo do texto pelos exemplos dados pelo autor, quase sempre relacionados ao contexto da liderança no âmbito político e dos movimentos sociais, onde a questão ético-moral é tomada em uma dimensão societal.
\end{abstract}

Palavras-chave: Liderança transformacional. Hermenêutica de profundidade. Contextualização. James MacGregor Burns.

\begin{abstract}
In Administration, leadership is linked to the interest in productive efficiency, assuming the capacity of leaders and subordinates to achieve organizational outcomes. However, leadership is an issue broader than what this conception can suppose. Understanding that this is the perspective adopted in the seminal text by Burns (1978) on transformational leadership, we propose in this study to revisit this work, in order to oppose its main arguments in relation to those made by transformational leadership authors in the field of Administration. To do this, we adopted the socio-historical analysis, as proposed by Stefani and Vizeu (2011), the first step of in-depth hermeneutics (THOMPSON, 2000), a method that aims to avoid the mistake of free interpretation of a work that is contextually situated. Thus, we conclude that the key point of transformational leadership, according to Burns, is the moral development issue and detachment in the utilitarian relationship between leader and subordinates. These two points are stressed throughout the text by means of the
\end{abstract}

Artigo recebido em 10 de setembro de 2013 e aceito para publicação em 18 de setembro de 2014.

DOI: http://dx.doi.org/10.1590/1679-395111016

${ }^{1}$ Mestre em Administração pela UNIGRANRIO; Professor do Curso de Administração da Escola de Ciências Sociais Aplicadas da UNIGRANRIO. Endereço: Rua da Lapa, 86 - 9० Andar - Lapa, CEP 20021-180, Rio de Janeiro - RJ, Brasil. Email: pedroalessandro@yahoo.com

2 Doutor em Administração de Empresas pela EAESP/FGV-SP; Professor Adjunto do Programa de Mestrado e Doutorado em Administração da Universidade Positivo. Endereço: Universidade Positivo - Rua Prof. Pedro Viriato Parigot de Souza, 5300, Campo Comprido, CEP 81280-330, Curitiba-PR, Brasil. Email: fabio.vizeu@gmail.com 
examples provided by the author, almost always related to the context of leadership in the political domain and that regarding social movements, where the ethical and moral issue is taken on a societal dimension.

Keywords: Transformational leadership. In-depth hermeneutics. Contextualization. James MacGregor Burns.

\section{Introdução}

Há muito tempo, o tema da liderança tem sido amplamente estudado por diferentes áreas e campos de saber. Dessas áreas, uma das mais profícuas tem sido a administração, que, sob a tutela de campos específicos de conhecimento e de prática profissional (particularmente, a psicologia organizacional e a área de recursos humanos) tem delineado programas de pesquisa sobre liderança que carregam premissas e interesses muito particulares. Assim, nos estudos gerencialistas - ou seja, a orientação acadêmico-científica que visa aprimorar a prática de gestão das organizações - a liderança é fortemente vinculada à eficiência produtiva, tendo como pressuposto fundamental a capacidade de líderes e liderados atingirem os resultados organizacionais (BERGAMINI, 1994), uma medida quase sempre traduzida por essa literatura de enfoque puramente econômico, de natureza financeira e motivação capitalista. Nesse sentido, o que marca a natureza da pesquisa gerencialista é o interesse técnico e utilitário na produção do conhecimento, visando ao controle instrumentalizado da realidade social (HABERMAS, 1975), especificamente, na esfera administrativa e organizacional.

De resto, sendo a presunção do cientificismo positivista a capacidade de previsão e controle (SANTOS, 1988) e configurando essa intenção uma importante marca da literatura de management (VIZEU, 2010), a liderança é observada como uma variável organizacional a ser medida e manipulada, tal qual tantas outras que surgem como diretrizes para os pesquisadores dessa área, que articulam seus estudos em torno de metodologias de base quantitativa e implicações pragmáticas para as empresas. ${ }^{3}$

Todavia, a liderança é matéria muito mais ampla do que pode julgar a literatura de base gerencialista. Como fenômeno social, a liderança se apresenta em relações e círculos sociais que extrapolam as dimensões da organização empresarial moderna. É por isso que vemos na literatura sobre esse tema a menção a líderes políticos, militares, religiosos, comunitários, ativistas e intelectuais, visando ao escrutínio de boas práticas e outras referências para o desenvolvimento de modelos e princípios de boa liderança. Assim, o escopo de investigação do fenômeno da liderança se amplia, mas exige do pesquisador maior cuidado quanto à apropriação indevida ou reducionista de perspectivas cunhadas em campos sociais e acadêmicos distintos da área de administração (MATITZ e VIZEU, 2012; STEFANI e VIZEU, 2011; WHETTEN, FELIN e KING, 2009).

Foi por conta dessa possibilidade de ampliação do escopo acadêmico que tornou-se notório na área de organizações uma teoria da liderança que foi apresentada pela primeira vez em um texto produzido pelo cientista político James MacGregor Burns. Considerado o texto seminal da chamada perspectiva da liderança transformacional (BASS, 1985; 1990; VILELA, 2012; VIZEU, 2011), o texto de Burns (1978) apresenta os fundamentos desse modelo e inaugura um dos mais profícuos campos de estudo de liderança dentro da área de administração. Vinculada às perspectivas da nova liderança (BRYMAN, 2009), a liderança transformacional é considerada um interessante contraponto à ortodoxia na área, expressa especialmente pelas vertentes dos traços, dos estilos e contingencial (BERGAMINI, 1994; BRYMAN, 2009; VILELA, 2012).

Realmente, a partir da proposta de Burns, um amplo campo de pesquisa organizacional sobre liderança foi aberto, especialmente, a partir da iniciativa de Bernard Bass, que traduziu para o âmbito corporativo e

${ }^{3}$ Basta ver a natureza dos estudos retratados pela revisão do campo da liderança, feita por Bergamini (1994). 
empresarial a perspectiva originalmente cunhada na esfera da liderança política e intelectual. Mais do que isso, Bass e seus colaboradores buscaram operacionalizar ferramentas que viabilizassem a pesquisa empírica sobre liderança transformacional, bem como garantir aos gestores de organizações empresariais parâmetros para identificá-la e promovê-la em suas organizações (VIZEU, 2011). Esse viés pragmático também foi a preocupação de Warren Bennis, que, mesmo nem sempre anunciando de forma explícita a influência de Burns (1978) em seus próprios estudos, reproduz o modelo transformacional de forma simples e voltada para o público corporativo (BENNIS, 1996; BENNIS e NANUS, 1988), feito este que contribui para que Bennis seja considerado um dos autores de liderança mais influentes no meio empresarial.

Apesar das contribuições dos esforços de continuidade ao trabalho seminal de Burns (1978), entendemos que estes não são isentos de problemas. Na verdade, a tradução de uma proposição teórica ao longo do tempo e em diferentes contextos acadêmicos pode configurar distorções em relação à proposta original, modificando, mesmo, o sentido dado pelo autor (MATITZ e VIZEU, 2012). Mesmo levando em conta que um texto tornase independente do autor à medida que é interpretado e reinterpretado, e que a legitimação do texto como forma de conhecimento válida se dá, antes, pela (re)leitura do que pelo suposto sentido original dado (GADAMER, 1997), é preciso considerar que as distorções provocadas pelas apropriações de propostas intelectuais alheias podem obscurecer a força de um argumento original.

Por entender a pertinência desse problema no caso do texto seminal de Burns (1978), propomos neste artigo revisitar essa obra, buscando contrapor seus principais argumentos àqueles formulados por alguns dos autores de liderança transformacional na área de administração. Com esse intento, adotamos um método específico, visando não cair no anacronismo tão comum na área de administração e organizações (MATITZ e VIZEU, 2012), aquele da livre interpretação de uma obra que é contextualmente situada e produzida. Assim, assumimos a perspectiva de Thompson (2000) apresentada em seu método de hermenêutica de profundidade, onde, para se analisar formas simbólicas (conceitos, teorias, linguagem ou mesmo textos), fazse necessário ter em conta que tais formas são produções sociais endereçadas para específicos contextos e audiências. A partir dessa premissa, seguimos o protocolo apresentado por Stefani e Vizeu (2011) sobre a análise sócio-histórica (ASH), para construir nosso frame analítico do texto de Burns (1978) e situar nossa crítica às traduções dessa obra existentes. Nesse sentido, por tradução entendemos a releitura da proposta teórica feita por Burns (1978) que foi empreendida pelos autores da área de administração. Utilizamos esse termo no sentido da hermenêutica, especialmente, segundo as propostas de Gadamer e Ricoeur.

Assim, além desta introdução, este artigo é dividido nas seções "Demarcação metodológica para análise teórica", "O autor e a época", "Reinterpretação da teoria de liderança de Burns" e na subseção "A recepção da teoria de liderança de Burns pelos autores gerencialistas", seguindo-se as "Considerações finais" e as "Referências".

\section{Demarcação Metodológica para Análise Teórica}

Como já foi mencionado, o método a que se recorreu para analisar a teoria de Burns (1978) foi a hermenêutica de profundidade, um protocolo metodológico sistematizado por Thompson (2000) para a apreciação de formas simbólicas, sejam elas ideologias, discursos ou mesmo teorias, como é o caso da que é analisada neste artigo. Como sugere o próprio autor, "esse referencial coloca em evidência o fato de que o objeto de análise é uma construção simbólica significativa, que exige uma interpretação" (THOMPSON, 2000 , p. 355). Na verdade, o grande problema que esse método pretende evitar é o da falta de crivo para a interpretação de um objeto definido por interpretações prévias: as formas simbólicas, expressas pela linguagem e que, apresentando significado atribuído socialmente, variam no tempo e no espaço a partir de diferentes interpretações. Assim, em diferentes contextos históricos e sociais, temos diferentes interpretações da mesma forma simbólica. É por isso que as formas simbólicas produzidas e reproduzidas pelos indivíduos em suas relações interpessoais são, ao mesmo tempo, produto do social e substrato de individuação. Produto do social, por serem constituídas na interação; substrato de individuação, por permitirem que as pessoas reconheçam os objetos do mundo onde vivem e, por isso mesmo, reconheçam a si mesmas. Isso foi bem 
capturado pelos hermeneutas de tradição fenomenológica, como, por exemplo, Gadamer (1997), que sugere que a interpretação de um texto é o que o define, não a autoria - ou, dito de outra forma, um texto clássico só se torna atemporal4 por conta, justamente, das diferentes interpretações em específicos contextos históricos. É por isso que vemos textos serem "esquecidos" por longos períodos na história para serem "descobertos" muitos anos após seu tempo.

Entretanto, não queremos com essa proposta menosprezar o valor da autoria; muito pelo contrário. Mesmo considerando a força da reinterpretação na definição das formas simbólicas - por exemplo, a interpretação de uma comunidade científica é fundamental para a legitimação de uma determinada teoria (MATITZ e VIZEU, 2012) - a autoria de determinada expressão intelectual é fundamental para revelar a própria essência desse objeto, tendo em conta que, quando algo é concebido por alguém, esse autor o faz com determinada intenção, visando determinada audiência e condicionado por determinado contexto.

É assim que, dentro de algumas correntes de história intelectual, apregoa-se a necessidade de investigar a contextualização histórica de um texto para se chegar aos significados originalmente atribuídos pelo autor. Esse é o caso, por exemplo, do contextualismo linguístico inglês, que tem como principal expoente Quentin Skinner (JASMIN, 2005). Sem desejar entrar na polêmica que cerca essa perspectiva, entendemos que a investigação do contexto de produção intelectual é peça fundamental para a verdadeira compreensão de um texto clássico, de uma teoria, de um gesto ou de uma ação; não só para se melhor assimilar a proposta do autor/sujeito que é agente do objeto de análise, mas também para se verificar com mais atenção as omissões e distorções da recepção dessa obra pelas audiências futuras. Por isso, a vida do autor e as condições de produção do objeto textual investigado são parte fundamental da própria compreensão desse mesmo objeto transformado ao longo do tempo. Essa condição é denominada por Thompson (2000) hermenêutica da vida cotidiana. Nas palavras do autor, "é um ponto de partida primordial e inevitável do enfoque da Hermenêutica de Profundidade" (THOMPSON, 2000, p. 363).

Assim, para dar conta da contextualização da proposta de Burns (1978) sobre liderança transformacional, seguimos o procedimento da análise sócio-histórica, a etapa da hermenêutica de profundidade que viabiliza essa demarcação. Como sugere Thompson (2000, p. 366), "o objetivo da análise sócio-histórica é reconstruir as condições sociais e históricas de produção, circulação e recepção das formas simbólicas". Essencialmente, é essa etapa que permite a apreciação de um objeto social e historicamente delimitado pelos seus produtores e usuários.

Considerando os procedimentos adotados para a viabilização da análise sócio-histórica, tais quais apresentados por Stefani e Vizeu (2011), foram dados os seguintes passos: em primeiro lugar, verificamos no próprio livro de Burns (1978) objeto de análise informações sobre o autor, quem o inspirou, seu perfil profissional; enfim, sua vivência em geral, entre outras coisas consideradas pelo autor como pertinentes para a compreensão do texto. O segundo passo foi levantar biografias do autor, bem como informações e dados complementares sobre seu perfil acadêmico, especialmente, em relação a sua atuação nas instituições acadêmicas e profissionais das quais faz ou fez parte. Quanto a essa questão, em particular, encontramos expressiva informação nos websites da Universidade de Maryland, do Williams College e da Academia de Liderança, organizações onde Burns trabalhou, todas nos EUA. Essas informações nos permitiram buscar em outros websites mais informações sobre a trajetória acadêmica de Burns e sobre sua obra. Nesse levantamento também encontramos vídeos, entrevistas e artigos que, entre outros assuntos, tratavam sobre a atuação política de Burns, seus cargos e funções, sua experiência na II Guerra Mundial, seus prêmios acadêmicos e seu trabalho como biógrafo de grandes líderes dos EUA. Neste levantamento, buscamos manter sempre o foco no tempo em que o autor viveu e quais acontecimentos marcaram sua época.

Um terceiro passo para a realização da análise sócio-histórica foi o levantamento de informações históricas relevantes sobre o país e o período correspondente à produção do texto de Burns (1978). Nesse sentido,

${ }^{4}$ Como sugerem Meneghetti, Guarido Filho e Azevedo (2012). 
consideramos para o nosso corte temporal as décadas de 1960 e 1970, pois, de acordo com o levantamento biográfico da vida acadêmica de Burns, foi nesse período que o autor testemunhou importantes eventos que deram ensejo à elaboração de sua teoria de liderança transformacional. Também foi nesse período que Burns publicou outros importantes livros correlacionados ao texto em análise, o que ratifica nossa escolha.

Para levantar os dados históricos dos EUA das décadas de 1960 e 1970, utilizamos referências bibliográficas da história norte-americana. Tendo em vista a dificuldade natural de um estrangeiro selecionar uma bibliografia relevante, nosso critério foi o de conveniência (livros e artigos disponíveis para consulta e aquisição). Seguimos com a apresentação de alguns dados relevantes sobre a análise sócio-histórica de Burns e sua teoria de liderança.

\section{O Autor e a Época}

O norte americano James MacGregor Burns nasceu em Melrose, Massachusetts, em 1918, e teve uma trajetória pessoal e profissional de destaque em diferentes áreas: foi professor, escritor, político, historiador, ativista e até ex-combatente de guerra. Recebeu seu $\mathrm{PhD}$ em ciência política pela Universidade de Harvard, e foi aluno da Escola de Economia de Londres. Ele é professor emérito de da Williams College, e ensina na Academia de Liderança, na Escola de Políticas Públicas da Universidade de Maryland. As informações coletadas indicam que esse centro de estudos tem por objetivo fomentar a liderança transformadora através de serviços de educação, erudição e consultoria, com especial atenção para o avanço da liderança de grupos historicamente sub-representados na vida pública. Burns também é membro da Academia Americana de Artes e Ciências, ex-presidente da Associação Americana de Ciências Políticas e também da Sociedade Internacional de Psicologia Política.

Em relação à sua obra intelectual, destaca-se o interesse em questões de liderança política e em biografias de grandes personalidades (BAILEY e AXELROD, 2001), tendo escrito 25 livros sobre esses temas e outros correlatos. Quanto a essa marca de Burns, pode-se vislumbrar seu interesse pelo tema já na época em que serviu na II Grande Guerra, quando se verificava em suas anotações no campo de batalha esse fascínio pelos grandes líderes militares e estadistas. No próprio livro Leadership, Burns menciona ter sido influenciado pela leitura de $O$ príncipe, de Maquiavel, na elaboração dos conceitos de liderança transacional e transformacional. Também vale destacar que Burns foi agraciado com um prêmio Pulitzer na categoria História com a biografia de Roosevelt, escrita em 1970.

Outras fontes consultadas reforçam a ideia da centralidade da guerra e das biografias de grandes líderes militares e políticos na constituição do texto de Burns (1978). Em entrevista ao professor George R. Goethals, professor da Jepson Escola de Estudos de Liderança, Burns declara que o seu interesse pelo tema liderança adveio das biografias lidas sobre grandes líderes mundiais, mas também pelo fato de ter estado no front da II Guerra Mundial. Nessa entrevista, Burns lembra que não somente participou de algumas operações de campo como combatente, mas que também atuou como historiador de combate no campo do Pacífico de 1943 a1946, tendo sido condecorado com a Estrela de Bronze e quatro estrelas da batalha. Nessa entrevista, Burns destaca também o fato de que geralmente só se ouve falar dos grandes comandantes, seus heroísmos e conquistas, mas que não ouvimos falar dos soldados, dos grandes praças que, no campo de batalha, têm atitudes de liderança que mudam o rumo da guerra, fazendo a fama dos generais.

Outro fato importante na trajetória pessoal de Burns foi sua atuação na política de seu país. Em 1958, foi o candidato democrata para o $1^{\circ}$ Distrito Congressional de Massachusetts e também foi eleito delegado para quatro convenções democratas (BAILEY e AXELROD, 2001). Esta atuação na política revela que Burns procurou ser um homem envolvido na prática daquilo que escrevia e que sua grande área de referência era o contexto político dos EUA. Não é por acaso que a maior parte das biografias que Burns escreve é de presidentes dos EUA, sendo seu texto mais premiado a biografia de Roosevelt, um presidente a que Burns recorre largamente em seu texto sobre liderança para ilustrar os modelos transacional e transformacional. Além disso, vale destacar que a atuação acadêmica de Burns ocorreu prioritariamente no âmbito das escolas 
de ciência política. Esse contexto acadêmico é fundamental para a compreensão da análise do texto de Burns (1978), e será retomada adiante.

Sobre os aspectos sociais e políticos da época de elaboração do texto Leadership, podemos destacar alguns eventos históricos correlacionados. Primeiro de tudo, o período das décadas de 1960 e 1970 é marcado pela tensão da Guerra Fria, por um lado, e por sucessivas crises políticas associadas a essa polaridade entre as duas potências nucleares. Os conflitos ao redor do mundo e as participações veladas dos EUA e da hoje extinta União Soviética (como foi o caso da chamada crise dos mísseis de Cuba, em 1962), as dificuldades na economia e a impopularidade das políticas de Estado (HOBSBAWM, 1994) contextualizaram uma crise de liderança política que, influenciou Burns tanto em sua decisão pelo engajamento direto na vida política quanto na formulação de sua teoria de liderança transformacional.

Dois importantes eventos da história política dos EUA ilustram essa crise de liderança (KARNAL, FERNANDES, MORAIS et al., 2007) no período de contextualização do livro de Burns sobre o tema. Um foi o assassinato do presidente John Fitzgerald Kennedy, um acontecimento polêmico que chocou toda a nação, que depositava suas expectativas nessa que foi considerada uma das grandes personalidades do século XX. De acordo com a literatura historiográfica dos EUA, a morte de Kennedy levou o país a desacreditar na possibilidade de mudanças em sua política, fato que aguçou a crise de liderança já instalada.

Outro evento diretamente associado à presidência dos EUA e que marcou a crise de liderança da época foi a renúncia do presidente Richard Nixon, em 1974, após a crise política gerada pelo chamado "caso Watergate" (JUST e CRIGLER, 2000). O episódio se configurou como um escândalo político por conta de atos de espionagem e roubo contra o partido de oposição, o partido democrata, nos quais Nixon teve envolvimento direto. Dadas as evidências do crime, Nixon renunciou, assumindo seu vice, Gerald Ford, que assinou a anistia de Nixon, isentando-o das responsabilidades legais por todos os crimes nos quais estivesse envolvido.

Associados a esses dois escândalos envolvendo presidentes dos EUA, as referências históricas consultadas lembram outros eventos marcantes do período, associados diretamente à política de Estado e ao governo do país: a crise financeira e social que eclode com a guerra do Vietnã (que se tornaria o maior fiasco bélico dos EUA) e as dificuldades para enfrentar a Guerra Fria e a Crise do Petróleo, que impactaram diretamente a economia interna do país e a vida do povo estadunidense (HOBSBAWM, 1994; KARNAL, FERNANDES, MORAIS et al., 2007).

Sobre a Guerra do Vietnã, destaca-se o fato de que três milhões de estadunidenses lutaram nessa guerra entre 1965 e 1973, e que os EUA gastaram US\$ 123 bilhões, tanto com a guerra quanto com a ajuda econômica ao Vietnã do Sul, gerando um déficit enorme no orçamento do país. Além disso, essa guerra mostrou que mesmo uma superpotência não é capaz de dispor de força e de recursos ilimitados. Já a crise do petróleo, iniciada em 1973, provocou longos anos de recessão nos EUA, além da desestabilização da economia mundial, situação que se agravou com a crise política no Irã e a consequente deposição do xá Reza Pahlevi, apoiado pelos EUA. A queda do xá, acabou desorganizando todo o setor de produção de petróleo no Irã, onde os preços do produto aumentaram em mais de 1.000\% (HOBSBAWM, 1994; KARNAL et al., 2007).

Nesse cenário de crises políticas, econômicas e ideológicas nos EUA das décadas de 1960 e 1970, James MacGregor Burns constitui seu pensamento sobre liderança transformacional, nitidamente influenciado pela crise de liderança no âmbito da política estadunidense. Diferentemente de seus sucessores nas pesquisas sobre liderança transformacional que escrevem seus textos nas décadas de 1980 e 1990 e são diretamente condicionados pelo contexto empresarial, Burns é influenciado por esse contexto político das décadas anteriores para a elaboração de sua teoria da liderança.

A partir dessa breve análise sócio-histórica, podemos empreender a análise da teoria de Burns, buscando reconhecer os elementos fundamentais da proposição teórica, tendo como referência os elementos de seu contexto de formação, sejam de sua época, sejam aqueles ressaltados na trajetória deste autor. Thompson (2000) chama essa análise de reinterpretação, por considerar uma nova leitura de algo já interpretado. A 
intenção é que busquemos elementos novos nessa análise do texto, para que possamos compará-la com as apreciações feitas pelos autores da orientação gerencial que tratam do modelo proposto por Burns.

\section{Reinterpretação da Teoria de Liderança de Burns}

Tendo em conta a trajetória acadêmica e intelectual de Burns, bem como seu contexto histórico de referência, verificamos que sua aproximação com o tema liderança se deu pelo seu interesse na habilidade de certos líderes políticos dos EUA em sensibilizar a população em torno de um ideal comum. O período histórico de referência da maturação intelectual da teoria de liderança de Burns é marcado pela consolidação da hegemonia econômica e militar dos EUA, mas também por sucessivas crises políticas internas. Nesse cenário, o povo estadunidense vê grandes líderes surgirem em torno de grandes causas, mas também se depara com líderes políticos incapazes de sensibilizar a nação e que geraram indignação e decepção diante da opinião pública (JUST e CRIGLER, 2000). Essa é a medida de referência de Burns para compreender o processo da liderança, especialmente, no contexto nacional. É assim que ele recupera abordagens teóricas psicológicas para constituir uma teoria de liderança moral, entendendo que essa é a questão central desse fenômeno no âmbito político.

Para Burns (1978), liderança é um fenômeno dual, onde o ato de liderar e o de seguir o líder se retroalimentam. Burns constitui sua teoria a partir dessa perspectiva de aproximação entre líder e liderados, pela ideia de que o ato de liderar envolve a criação de novos líderes a partir das pessoas que estão ao redor, envolvendo-as não apenas com as tarefas rotineiras, mas dando às mesmas, além de reconhecimento, perspectivas e condições de desenvolvimento da capacidade de tomada de decisão. A essa forma de liderança, Burns cunha a denominação transformacional, e que se associa com o estilo de liderança adotado pelos grandes estadistas nos quais Burns se inspira para desenvolver sua teoria.

Para retratar o contexto de emergência da liderança transformacional, Burns destaca as situações de crise onde se faz necessário um direcionamento moral da nação. $\mathrm{O}$ autor menciona como exemplos desses contextos favoráveis ao líder transformacional a Grande Depressão de 1929 e a II Grande Guerra, situações nas quais a tendência é aflorar nas pessoas um sentimento agregador, de ajuda mútua. Segundo Burns (1978), a crise social é o contexto ideal para o surgimento de comportamentos transformacionais, seja por parte das lideranças, seja por parte do homem comum da nação. Sobre esse modelo, o autor afirma: "Liderança transformacional ocorre quando uma ou mais pessoas se envolvem uns com os outros, de tal maneira que os líderes e seguidores motivam uns aos outros a níveis mais elevados de motivação e moralidade" (BURNS, 1978, p. 27). Como já foi mencionado, Burns reconhece nesse modelo a centralidade do conteúdo moral, aspecto esse que media a relação entre líder e liderados. Nesse sentido, Burns considera central o envolvimento do líder e dos seguidores em um ideal comum, bem como a não polarização da relação entre ambos.

Essa imagem não polarizada entre líder e liderados é ressaltada por Burns em uma rápida menção feita a Weber e a seu conceito de liderança carismática. Burns se afasta da suposta concepção de Weber sobre carisma como uma qualidade mágica que reside no líder, dado por uma graça divina. Sobre esse atributo, Burns relata (1978, p. 244):

A liderança heroica significa acreditar no líder por causa de seu personagem, independentemente de verificar suas capacidades técnicas, experiência ou opiniões; a fé na capacidade do líder em superar obstáculos e crises; prontidão para conceder aos lideres o poder de lidar com as crises; apoio total a esses líderes expresso por votos, aplausos, cartas, apertos de mão, tudo isso independentemente das instituições intermediárias. Então, a liderança heroica não seria simplesmente uma qualidade possuída por alguém, mas uma forma de relacionamento entre líder e liderado. 
Nesses termos, o conceito central para a compreensão da teoria de liderança de Burns (1978) é o de liderança moral. A partir dessa qualificação, Burns reconhece que valores são necessários na mediação das relações de liderança, e que estes estão sempre em conflito. Quando os valores morais públicos são priorizados, o efeito da liderança é sua capacidade de transcender o que os liderados querem individualmente, levando-os ao desenvolvimento moral, já que esse estilo possibilita que estes mudem regras, decisões, escolhas, valores, estilos, tudo de forma consciente. Burns lembra que a capacidade de uma nação superar seus problemas reside nessa visão de valores morais públicos, de que o interesse do individuo não pode prevalecer sobre os interesses da sociedade na qual ele está inserido.

Para contrapor as formas de liderança que não apresentam esse conteúdo moral como elemento mediador da relação entre líder e liderado, sinalizando assim que nem toda relação de liderança é transformacional, Burns (1978) cunha o termo transacional, inspirado na leitura de $O$ príncipe, de Maquiavel, e de sua descrição do comportamento de um estadista. Recuperando a metáfora da raposa e do leão, Burns explora essas imagens para descrever seus dois tipos de liderança. Sobre o comportamento da "raposa", lê-se em Maquiavel (1998, p. 42):

A um príncipe nunca faltam desculpas legítimas para explicar suas violações de fé. A história moderna fornecerá inumeráveis exemplos desse comportamento, mostrando como o homem consegue seu melhor se souber como jogar com seu lado raposa. Mas é uma parte necessária da natureza humana que você deve esconder com cuidado, devendo ser um grande mentiroso e hipócrita. Os homens são tão simples de espírito, e tão dominados por suas necessidades imediatas, que um homem fraudulento sempre vai encontrar muitos que estão prontos para ser enganados.

Com essa imagem, Burns constitui o contraponto à liderança transformacional: lideres também podem ser transacionais, baseando sua capacidade de influência na manipulação de recursos para o atendimento dos interesses individuais dos envolvidos. Assim, a influência sobre os seguidores é garantia pela barganha, pela transação, pelos favores, pelo benefício mútuo. Aqui, o líder surge como um grande articulador, um estrategista, como alguém que usa do poder que lhe é atribuído para garantir a obediência dos seguidores.

Já na liderança transformacional, o elemento que garante a obediência dos seguidores é a habilidade do líder em exaltar um ideal comum compartilhado pelo grupo. Nesse caso, o papel do líder é o de estimular o interesse por esse ideal, pelo crescimento moral, pelos valores compartilhados pelo grupo, e não simplesmente o interesse pessoal e individualista. A relação é mediada por uma causa comum, por valores morais compartilhados e compreendidos como importantes por todos. O líder passa a ser um sujeito que reforça esses valores, podendo mesmo ser responsável por fazê-los emergir no grupo. Para isso, é necessário que se compreenda a matriz teórica da psicologia moral de que Burns se serve para descrever o processo de influência da liderança transformacional.

Ao descrever a estrutura da liderança moral e a matriz psicológica da liderança, Burns fundamenta-se nos trabalhos de Lawrence Kohlberg e de Abraham Maslow, ambos renomados psicólogos e professores de Harvard. Maslow ficou conhecido por sua teoria de necessidades e Kolberg ganhou destaque por sua teoria do desenvolvimento moral. Basicamente, Maslow (1943) defende que as necessidades humanas se organizam em uma hierarquia; ou seja, a aparição de uma necessidade normalmente acontece quando ocorre a satisfação de outra necessidade anterior. Maslow (1943) apresenta as necessidades humanas nas seguintes categorias: as fisiológicas e de segurança, a de amor, a de afeição e pertencimento e, então, as necessidades de estima, fechando com as de autorrealização, o ponto mais alto de sua escala. Essa última é considerada por Burns (1978) para retratar a motivação na liderança transformacional, sendo retratada da seguinte forma por Maslow (1943, p. 379):

Mesmo que todas as necessidades anteriores sejam satisfeitas, podemos ainda muitas vezes (se não sempre) esperar que um novo descontentamento e agitação em breve desenvolva-se, a menos que o indivíduo esteja fazendo o que ele tem o dom ou nasceu para fazer. Um 
músico deve fazer música, um artista deve pintar, um poeta deve escrever, se é para ser finalmente feliz. O que um homem pode ser, ele deve ser. Esta necessidade podemos chamar de autorrealização.

Já Kolberg se ateve à investigação de uma escala de desenvolvimento moral. Após pesquisas feitas no centro de Estudos de Educação Moral, em 1971, Kolberg apresenta seu modelo de seis estágios de desenvolvimento moral, seguindo o modelo de desenvolvimento cognitivo da criança de Piaget. Para Piaget, as crianças somente mudavam de fase se estivessem preparadas para assimilar a nova fase, restando aos educadores e pais o desafio de estimular a curiosidade e interesse dos aprendizes. Também influenciado pelos filósofos estadunidenses Dewey e Baldwin, Kolberg constitui seu modelo dando ênfase no fato de que os indivíduos se desenvolvem progressivamente, em termos filosóficos e psicológicos.

Segundo Kohlberg (1971), o indivíduo progride no seu raciocínio moral, isto é, nas suas bases de comportamento ético, através de uma série de etapas. Assim, Kolberg propõe que o desenvolvimento moral ocorre em seis estágios identificáveis, que poderiam ser mais geralmente classificados em três níveis. O primeiro nível é o Pré-convencional (estágio 1: obediência e punição; estágio 2: individualismo, instrumentalismo e troca). O segundo nível, o Convencional (estágio 3: "bom garoto"; estágio 4: a lei e a ordem). No terceiro nível, o Pós-convencional (estágio 5: contrato social e estágio 6: consciência ética).

Nessa progressão, o ser humano partiria do nível um, no qual, em seu primeiro estágio, agirá conforme um sistema de recompensas e castigos (fazendo o "certo" sem ter consciência de retidão, mas por temer quem teria o poder de castigar) e no segundo estágio, motivado pela consciência da possibilidade de barganha, como num mercado de trocas. No nível dois, surgiria o interesse pela aprovação das pessoas que lhe são caras, para, num nível mais avançado, respeitar a lei e a ordem determinadas pelas autoridades e instituições sociais. Finalmente, no Pós-convencional, o indivíduo se esforça para adotar, como seus, valores morais adotados pela sociedade, voltando-se, num estágio mais avançado, para os princípios éticos universais, pelos quais se pensa no ganho de todos, acima dos próprios ganhos individuais.

Sobre a questão da progressão implícita nas teorias de Maslow, Kolberg e Piaget, Burns apresenta uma ressalva. Ele considera que o ser humano não apenas evolui na escala de valores, mas que também pode regredir. Nessa situação em particular, Burns destaca o papel da motivação do líder transformacional para que o seguidor assuma seu desenvolvimento moral no sentido crescente. Burns (1978) critica as hierarquias de Maslow e Kohlberg por serem unidirecionais e irreversíveis, onde as pessoas se movem pelos níveis em variadas velocidades, mas em apenas uma direção. Para Burns, as pessoas também podem regredir na escala, dependendo das condições em que se encontram e de sua própria vontade. Nesse ponto, Burns critica o interesse implícito nos trabalhos de Kohlberg e Maslow pela mera descrição e mensuração de escalas e do nível onde o indivíduo se encontre nas mesmas. O autor acredita que essas teorias devem levar à compreensão de como o indivíduo pode chegar ao próprio desenvolvimento moral e à consciência sobre si mesmo, gerando crescimento.

Como foi mencionado, ao descrever a matriz psicológica da liderança, Burns se inspira nas teorias de Maslow e Kohlberg, ora usando-as como fundamento, ora criticando-as, mas buscando constituir uma base teórica para revelar que o processo de liderança envolve uma influência em torno de um desenvolvimento moral e ético. É especialmente no trabalho de Kohlberg e de Piaget que Burns acredita estar o fundamento da motivação pelo desenvolvimento moral, tendo em conta a constatação desses psicólogos de que as crianças são estimuladas pela sociedade a buscar os estágios morais e cognitivos mais altos. É em torno desse desenvolvimento moral que reside o princípio fundamental da influência de líderes transformacionais, segundo Burns (1978). E isso nem sempre é observado pelos autores gerencialistas interessados na liderança transformacional, como será observado a seguir. 


\section{A recepção da teoria de liderança de Burns pelos autores gerencialistas}

Apesar da origem do termo "liderança transformacional" ser atribuída à obra de Burns (1978), a expressão foi popularizada na literatura gerencialista pela obra de Bernard Bass e seus colaboradores, de tal forma que o modelo dicotômico transacional e transformacional é reconhecido pelos revisores dos estudos de liderança em organizações como uma das mais importantes abordagens na perspectiva da "nova liderança", que surge em contraponto à terceira corrente da ortodoxia em estudos da liderança, vinculada à perspectiva contingencial (VILELA, 2012). Na verdade, a força da perspectiva de Bernard Bass sobre liderança transformacional na literatura gerencialista é tão grande que é comum o equívoco de reconhecê-lo como o proponente do termo ${ }^{5}$, a despeito do próprio Bass (1985) atribuir o termo a Burns (1978).

Sobre esse ponto, Vizeu (2011) considera que Bass e seus seguidores foram importantes porque buscaram operacionalizar a perspectiva de Burns (1978) para o mundo organizacional. Realmente, foi a partir de Bass que surgiram diversos estudos empíricos sobre liderança transformacional, especialmente, tendo em conta as ferramentas de mensuração desenvolvidas por este autor e seus colaboradores. A esse respeito, percebe-se a forte presença da orientação positivista dos estudos de psicologia organizacional na literatura de liderança transformacional, expressa especialmente pela pretensão de se revelar a verdade dos fenômenos sociais pela mensuração e testificação de hipóteses, algo somente possível por meio de instrumentos quantitativos e cientificamente validados, como supostamente é o caso das escalas desenvolvidas por Bass e seus colaboradores (BASS, 1985; 1990; BASS e AVOLIO, 1990; 1999).

Para melhor dimensionar a recepção do conceito de liderança transformacional na literatura gerencialista, recorremos à ideia de léxico especializado, apresentada por Matitz e Vizeu (2012). Os autores entendem que a tradução de um termo ou conceito na área de estudos organizacionais e administração costuma ser feita tendo-se em conta as orientações epistemológicas dessa área, o que pode significar a omissão (ou mesmo distorção) de aspectos importantes nos conceitos originais. Segundo Matitz e Vizeu (2012), a própria diversidade nas significações dos conceitos em estudos organizacionais se deve à multiplicidade de campos de empréstimo teórico-conceitual de que essa área se serve. Todavia, há um cerne epistemológico que orienta a apropriação desses conceitos e que acaba por normalizar os conceitos advindos de outros campos às principais linhas epistemológicas do mainstream de estudos organizacionais e da administração. Entendemos, assim como Vizeu (2011), que essa adaptação ocorreu com o conceito de liderança transformacional, emprestado de um autor de ciência política para o campo gerencial por pesquisadores da psicologia organizacional.

Como já foi mencionado, a principal adaptação feita no conceito de liderança transformacional diz respeito a sua operacionalização como um conjunto de traços observáveis no contexto organizacional. É assim que a grande contribuição de Bass e seus seguidores reside na constituição de uma ferramenta de mensuração de traços transformacionais ou transacionais em líderes organizacionais.

A partir dessa verificação, Bass (1990) defende que, através de treinamento, gerentes podem aprender técnicas e obterem as qualidades de que precisam para tornarem-se líderes transformacionais. Isto é, a pretensão de Bass ao usar o modelo transformacional de Burns (1978) é criar mecanismos de desenvolvimento de líderes organizacionais, seguindo a premissa positivista do mainstream do conhecimento técnico-cognitivo de prever e controlar (HABERMAS, 1975; SANTOS, 1988). Nesse interesse pragmático, desconsidera-se a importância dada por Burns à questão moral no estabelecimento da liderança transformacional, bem como ao fato de que esse modelo se fundamenta na relação dual entre o líder e seus seguidores.

A orientação utilitária e instrumental dada por Bass ao modelo de liderança transformacional também se explica pelo seu background acadêmico. Tendo obtido seu $\mathrm{PhD}$ em psicologia industrial em 1949 pela

${ }^{5}$ Por exemplo, como faz Robbins (2005). 
Universidade Estadual de Ohio, Bass constitui toda sua carreira acadêmica dentro da área de management: além de ter coordenado uma pesquisa mundial sobre management para o desenvolvimento de um programa de treinamento e formação, patrocinado pela Fundação Ford, foi consultor e coordenou treinamento de executivos para muitas empresas listadas entre as 500 maiores da revista Fortune. É reconhecido e citado no mundo todo por seu trabalho no campo da liderança, tendo recebido milhões de dólares em bolsas de estudo e pesquisa. Focou os últimos 25 anos de vida em pesquisas e aplicações para o desenvolvimento de liderança transformacional no management. É reconhecido também por sua contribuição para a psicologia organizacional, trabalhos diversos sobre o papel da liderança nos resultados das organizações e gestão participativa.

Para Bass e seus colaboradores, o aspecto central da liderança transformacional é o resultado organizacional extraordinário obtido através desse estilo. Para Bass (1985), a relação entre o líder transformacional e seus seguidores é aquela que consegue estimular os liderados a realizar mais do que fariam em uma relação transacional. Por esse motivo, Bass enfatiza em sua análise da liderança transformacional supostos traços do líder, assumindo uma visão comportamentalista do fenômeno da liderança transformacional. Esse reducionismo já havia sido identificado por Vizeu (2011), em relação às limitações da leitura comportamentalista feita pelos autores gerencialistas do modelo de liderança transformacional:

Os limites dessa perspectiva residem especialmente na tentativa de revigorar a visão de um líder herói e onipotente, que representa a única fonte de sucesso da liderança. Em grande parte, isso é culpa da orientação dada aos estudos dessa abordagem, que priorizam o levantamento de "traços" do líder transformacional (especialmente a corrente de Bass e seus seguidores), algo perigoso quando instrumentalizado para atender aos interesses das grandes corporações, que, diante dessa possibilidade, desejam construir mecanismos e ferramentas objetivas para a seleção de "super" líderes, tal qual foi pretendido pelos estudos de liderança que predominaram no início do século XX. (VIZEU, 2011, p. 73)

De fato, ao contrapormos os pontos priorizados por Bass e seus seguidores, vemos a liderança transformacional reduzida aos seus traços, tais como o carisma, a inspiração, o estímulo intelectual e a consideração individualizada (BASS, 1990). De acordo com Bass e seus seguidores, é a partir desses traços que se estabelece a liderança transformacional, dentro do contexto gerencial. Isso pode ser observado no seguinte relato do autor sobre o contexto de influência da liderança transformacional em organizações econômicas:

Em relação ao estagiário, o estilo de gestão do seu primeiro supervisor pode fazer uma grande diferença em sua carreira e posterior sucesso. Por exemplo, seis anos depois de se juntarem a Exxon, muitos gestores que foram avaliados por seus supervisores relataram que tinham sido dadas tarefas desafiadoras pelo seu supervisor inicial (ou seja, que tinham recebido a consideração individualizada). Muitos haviam atribuído aos supervisores a boa reputação da empresa. É importante notar que os gestores tendem a modelar o seu próprio estilo de liderança seguindo seus supervisores imediatos. Assim, se mais superiores são transformacionais, mais funcionários de nível inferior vão emular o comportamento transformacional - e, provavelmente, irão agir como líderes transformacionais à medida que sobem na organização. (BASS, 1985, p. 8)

Para sistematizar a liderança transformacional em estudos empíricos, Bass constitui uma escala de mensuração que denomina multifactor leadership questionnaire (MLQ), onde o autor elabora um questionário que quantifica traços transformacionais e transacionais, polarizando esses dois estilos. Nesse instrumento de verificação de estilos, Bass associa em publicações posteriores (BASS e AVOLIO, 1990; 1993) o estilo de liderança com a eficácia do líder, entendida eficácia a partir do momento em que os resultados organizacionais são atingidos. É interessante notar que, nesse aspecto, a liderança transacional é compreendida como um estilo que também atinge resultados, porém de forma diferente da transformacional; 
argumento esse muito próximo daquele defendido pelos autores da abordagem contingencial da liderança (BERGAMINI, 1994; VILELA, 2012).

Ou seja, na apropriação feita por Bass e seus colaboradores do modelo de liderança transformacional cunhado por Burns (1978), o fenômeno da liderança ainda é centrado nas competências do líder. Mais uma vez, considerando a perspectiva gerencialista dos estudos de liderança, onde persiste o interesse instrumental pela seleção e treinamento de gestores, essa ênfase apresenta-se como coerente. Todavia, dada a leitura do texto de Burns (1978) e tendo por referência a hermenêutica de profundidade (THOMPSON, 2000), há uma evidente omissão do aspecto central da proposta original, que é a construção de uma relação social baseada no desenvolvimento moral. A relação de liderança passa a ser garantida pelo estado pós-convencional assumido pelo líder e pelos seus seguidores, no qual os valores ético-morais compartilhados pelo grupo passam a ser mais importantes do que os interesses individualistas. É assim que Burns se refere aos líderes políticos, aos movimentos sociais, às guerras, para ilustrar o modelo de liderança que ele identificou na sociedade.

Ao transpor esse modelo para o contexto organizacional, os autores gerencialistas - especialmente Bernard Bass - olvidam ser a liderança transformacional uma liderança de cunho moral, baseada no conceito de "valores morais públicos" (BURNS, 1978). No contexto organizacional, onde predomina o interesse utilitarista e a orientação para o mercado, os valores substantivos da sociedade são comumente esquecidos (RAMOS, 1989). Isso se verifica na tradução feita pelos autores gerencialistas do conceito de liderança moral de Burns. Por exemplo, quando Bass e seus colaboradores mencionam a transformação dos liderados, geralmente, o fazem em relação ao sucesso em sua carreira, em relação ao seu crescimento pessoal e profissional, não sendo mencionada a questão do desenvolvimento moral no estágio pós-convencional de Kolberg, algo central na visão de Burns (1978). A motivação está quase sempre associada ao significado do trabalho, aos resultados organizacionais determinados pelo léxico especializado das áreas de recursos humanos e psicologia organizacional (desempenho no trabalho, satisfação no trabalho etc.).

Diferentemente dessa perspectiva, Burns (1978) constitui sua ideia de liderança baseada em grandes líderes da sociedade que inspiram seus seguidores a assumir os valores e princípios morais substantivos da sociedade, sejam para enfrentar uma guerra em nome do patriotismo e da liberdade, seja para acatar decisões austeras de um governo para sair de uma crise econômica e garantir o bem-estar de toda a população. Na literatura organizacional, esses valores societários são substituídos pelos valores da organização. Isso, além de representar uma leitura equivocada da proposta de Burns (1978), que via na liderança transformacional uma forma de emancipação dos seguidores, também pode significar uma visão manipuladora dos liderados. Sobre esse aspecto, a literatura de crítica ao management costuma denunciar as estratégias de manipulação da subjetividade dos trabalhadores pela organização através da identificação destes com os objetivos organizacionais (ENRIQUEZ, 1997; FARIA e MENEGHETTI, 2007). A contradição dessa vinculação está na não conformidade dos interesses organizacionais com os valores substantivos do indivíduo e da sociedade (RAMOS, 1989).

\section{Considerações Finais}

Esta apreciação da proposta original de Burns (1978) sobre a liderança transformacional, longe de ser uma apologia ao autor e a sua obra, teve por objetivo central revelar pontos obscuros no empréstimo conceitual feito pelos pesquisadores de liderança da área organizacional. Assim, ao proceder com a análise sóciohistórica deste texto seminal, pudemos verificar que, muitas vezes, há significativas diferenças entre o conceito de liderança transformacional tal qual apresentado pela literatura de Administração e a proposta original de Burns.

Para viabilizar nossa avaliação do texto em que Burns apresenta sua teoria da liderança transformacional, recorremos ao método desenvolvido por Thompson (2000) para análise de formas simbólicas. Partindo da premissa de que os produtos sociais - tais como a linguagem, a teoria, o conceito e a obra de arte, entre 
outros - são formas pré-interpretadas, Thompson se inspira na hermenêutica para desenvolver um protocolo de análise contextualizado, que pretende chegar a um dimensionamento mais acurado do contexto de produção e transmissão das formas simbólicas. Através dessa metodologia, pode-se delinear uma nova interpretação, onde se apontam questões nem sempre observadas pelas interpretações livres de conteúdos simbólicos, empreendidas pelos sujeitos que se servem das formas simbólicas em seu próprio contexto social.

Assim, tivemos a intenção de realizar a análise da teoria de liderança de Burns (1978) verificando os fundamentos sócio-históricos de sua produção. Com esse intento, recuperamos a trajetória acadêmica e profissional do autor, bem como o contexto histórico de sua época. Assim procedendo, pudemos verificar que Burns (1978), sendo um autor de ciência política e tendo vivido o conturbado período de crises políticas nos EUA entre as décadas de 1960 e 1970, constituiu sua teoria da liderança tendo por referência as grandes lideranças políticas e militares da história, em especial, da história dos EUA.

Essa contextualização sócio-histórica nos permitiu ler o texto de Burns com outro olhar, reconhecendo pontos destacados pelo autor que são ressaltados pelo conhecimento prévio sobre o contexto de produção do texto. Assim, chegamos ao entendimento de que o ponto central da liderança transformacional, para Burns, é a questão do desenvolvimento moral e o distanciamento com a relação utilitária entre líder e liderados. Esses dois pontos são reforçados ao longo do texto pelos exemplos dados pelo autor, quase sempre relacionados ao contexto da liderança no âmbito político e dos movimentos sociais, onde a questão ético-moral é tomada em uma dimensão societal.

Por outro lado, nossa análise da obra de Burns (1978) nos permitiu verificar a forma como esse conceito foi traduzido para a área gerencial, indicando, grosso modo, a omissão de seus pontos fundamentais, que foram destacados em nossa análise. Assumindo ser o esforço aqui empreendido, apenas, uma tentativa de análise da obra, reconhecemos nosso estudo como um primeiro passo para que se busque um novo olhar sobre o estudo do modelo de liderança transformacional no âmbito das organizações. De forma alguma pretendemos com essas breves considerações inviabilizar o uso do conceito nos estudos organizacionais. Apenas destacamos, de forma provocativa, que há questões a serem consideradas quanto ao uso desse conceito - pelo menos, da forma como ele foi proposto originalmente - no âmbito das organizações econômicas.

É necessário que se vislumbre, assim, uma visão menos ingênua do fenômeno da liderança nas organizações, capaz de abranger toda a complexidade da vida humana em sociedade. Conforme buscamos demonstrar em nossa argumentação, persiste na literatura do mainstream sobre liderança, a redução do fenômeno às questões personalísticas. Trata-se muitas vezes de uma redução determinada pelo interesse de consultorias em venderem produtos sedutores e de fácil operacionalização, embora falaciosos e ingênuos.

Cabe observar que liderança transformacional não é uma teoria, o que exigiria pesquisas mais abrangentes e metodologia científica para se sustentar. Trata-se de um termo, um ideia surgida das experiências vividas em campo e pelo autor no referido período de sua vida. É importante pensar, também, que a abordagem foi desenvolvida num certo contexto político, conturbado por crises políticas nos EUA. Nesse sentido, a proposta metodológica deste artigo é fazer uma análise sócio-histórica - a qual demanda análise e ajustes -, ao tentar enquadrar nos traços da cultura brasileira (personalismo, distância hierárquica, "jeitinho", entre outros). Neste sentido, é possível se pensar em estudos futuros que delineiem a teoria e prática da liderança no Brasil a partir deste contexto.

As limitações do estudo estão: a) na quantidade de autores utilizados para a comparação, pois com uma amostra maior é possível aproximar-se mais de uma análise investigativa mais abrangente e b) na dificuldade de aplicar um método investigativo que visa extrair apenas os fatos, com imparcialidade, pois a tendência do analista, mesmo com a aplicação de um método racional, é, em um ou outro momento, deixar-se levar por sua base de conhecimentos, escala de valores etc.

Em relação a futuros projetos fica a sugestão de que haja um aprofundamento de estudos sobre como são formados na mente e construídos na realidade do indivíduo os contextos que podem influenciar os resultados 
obtidos pelo líder transformacional. Assim, pode-se ter uma visão mais complexa e crítica do tema, permitindo que a dialética traga uma evolução da percepção deste líder transformacional. Ainda quanto a estudos futuros, cabe ressaltar o quanto é comum na abordagem do tema o foco excessivo no líder, creditando-se a ele todo o mérito ou demérito pelos resultados obtidos. Nesse sentido, é possível discorrer sobre a necessidade de uma conotação pedagógica para dividir esse peso entre os liderados. Segundo Freire (1970), a educação é mais que uma técnica, mais que uma formalidade. Ainda segundo esse autor, através do construtivismo, o indivíduo conscientiza-se de seu lugar na sociedade e dos caminhos para a transformação de sua existência, tornando-se ativo, em vez de vítima passiva dos fatos. Trabalhando juntos, líderes e liderados compartilham experiências e constroem uma identidade em grupo.

Finalmente, gostaríamos de destacar que nosso esforço cumpre também um exercício metodológico da análise sócio-histórica aplicada ao estudo do pensamento administrativo, tal qual propõem Stefani e Vizeu (2011). A questão dos problemas da não apreciação metodológica em estudos de cunho teórico é um problema que persiste na área de administração. Entendemos ser necessário avançarmos nesse sentido, provendo a área de recursos para uma análise epistemológica mais acurada.

\section{Referências}

BAILEY, J.; AXELROD, R. H. Leadership lessons from Mount Rushmore: an interview with James MacGregor Burns. Leadership Quarterly, v. 12, n. 1, p. 113-121, 2001.

BASS, B. M. Leadership and performance beyond expectations. New York: Free Pres, 1985.

BASS, B. M. From transactional to transformational leadership: learning to share the vision. .Organizational Dynamics, v. 18, n. 3, p. 19-31, 1990.

BASS, B. M.; AVOLIO, B. J. The implications of transactional and transformational leadership for individual, team, and organizational development. Research in Organizational Change and Development, v. 4, p. 231-272, 1990.

BASS, B. M.; AVOLIO, B. J. Transformational leadership and organizational culture. Public Administration Quarterly, v. 17, n. 1, 12-121, 1993.

BASS, B. M.; AVOLIO, B. J. Re-examining the components of transformational and transactional leadership using the multifactor leadership questionnaire. Journal of Occupational \& Organizational Psychology, v. 72, n. 4, 441-462, 1999.

BENNIS, W. A formação do líder. São Paulo: Atlas, 1996.

BENNIS, W.; NANUS, B. Líderes: estratégias para assumir a verdadeira liderança. São Paulo: Harbra, 1988.

BERGAMINI, C. W. Liderança: administração do sentido. São Paulo: Atlas, 1994.

BRYMAN, A. Liderança nas organizações. In: CLEGG, S. R.; HARDY, C.; NORD, W. R. (Org.). Handbook de estudos organizacionais. São Paulo: Atlas, 2009 v. 3, 257-281 p.

BURNS, J. M. Leadership. New York: Perenium, 1978.

ENRIQUEZ, E. O indivíduo preso na armadilha da estrutura estratégica. Revista de Administração de Empresas, v. 37, n. 1, 18-29, 1997.

FARIA, J. H.; MENEGHETTI, F. K. O sequestro da subjetividade. In: FARIA, J. H. (Org.). Análise crítica das teorias e práticas organizacionais. 1. ed. São Paulo: Atlas, 2007. 45-67 p.

GADAMER, H. G. Verdade e método. Petrópolis: Vozes, 1997. v. I. 
HABERMAS, J. Conhecimento e interesse. In: HABERMAS, J. Textos escolhidos. São Paulo: Abril Cultural, 1975. 291-302 p.

HOBSBAWM, E. A era dos extremos. São Paulo: Companhia das Letras, 1994.

JASMIN, M. G. História dos conceitos e teoria política e social: referências preliminares. Revista Brasileira de Ciências Sociais, v. 20, n. 57, p.27-38, 2005.

JUST, M.; CRIGLER, A. Leadership image-building: after Clinton and Watergate. Political Psychology, v. 21, n. 1, p. 179-198, 2000.

KARNAL, L. et al. História dos Estados Unidos: das origens ao século XXI. Rio de Janeiro: Editora Contexto, 2007.

KOHLBERG, L. From is to ought: how to commit the naturalistic fallacy and get away with it in the study of moral development. New York: Academic Press, 1971.

MAQUIAVEL, N. O príncipe. Rio de Janeiro: Hemus, 1998.

MASLOW, A. H. A theory of human motivation. Psychological Review, v. 50, n. 4, p. 370-396, 1943.

MATITZ, Q. R. S.; VIZEU, F. Construção e uso de conceitos em estudos organizacionais: por uma perspectiva social e histórica. Rev. Adm. Pública, v. 46, n. 2, p. 577-598, 2012.

MENEGHETTI, F. K.; GUARIDO FILHO, E. R.; AZEVEDO, A. Por que ler os clássicos nos estudos organizacionais? In: ENCONTRO DE ESTUDOS ORGANIZACIONAIS - EnEO, 7. 2012, Curitiba. Anais... Curitiba: ANPAD, 2012.

RAMOS, A. G. A nova ciência das organizações: uma reconceituação da riqueza das nações. 2. ed. Rio de Janeiro: FGV, 1989.

ROBBINS, S. P. Comportamento organizacional. 11. ed. São Paulo: Pearson, 2005.

SANTOS, B. S. Um discurso sobre as ciências na transição para uma ciência pós-moderna. Estudos Avançados, v. 2 , n. 2, p. 46-71, 1988.

STEFANI, D.; VIZEU, F. Contribuições da análise sócio-histórica à pesquisa organizacional e da Administração. In: ENCONTRO DE ENSINO E PESQUISA EM ADMINISTRAÇÃO E CONTABILIDADE DA ANPAD, 3. 2011. João Pessoa. João Pessoa: ANPAD, 2011.

THOMPSON, J. B. Ideologia e cultura moderna: teoria social critica na era dos meios de comunicação de massa. 5. ed. Petrópolis: Vozes, 2000.

VILELA, J. R. P. X. O líder e a liderança: uma investigação orientada pela dialética negativa de T. W. Adorno. 2012. 541 f. Tese (Doutorado em Administração) - Pontifícia Universidade Católica - PUC de Minas Gerais, Belo Horizonte, 2012.

VIZEU, F. (Re)contando a velha história: reflexões sobre a gênese do management. Revista de Administração Contemporânea, v. 14, n. 5, p. 780-797, 2010 .

VIZEU, F. Uma aproximação entre liderança transformacional e teoria da ação comunicativa. Revista de Administração da Mackenzie, v. 12, n. 1, p. 53-81, 2011.

WHETTEN, D. A.; FELIN, T.; KING, B. G. The practice of theory borrowing in organizational studies: current issues and future directions. Journal of Management, v. 35, n. 3, p. 537-563, 2009. 